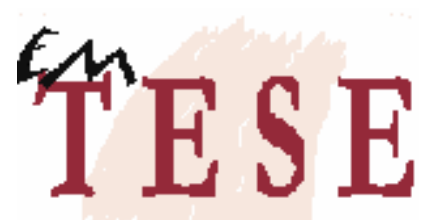

Revista Eletrônica dos Pós-Graduandos em Sociologia Política da UFSC

Vol. 4 n. 2 (2), janeiro-julho/2008

ISSN 1806-5023

\title{
Trabalho Invisível
}

Soraya Franzoni Conde ${ }^{1}$

\section{RESUMO}

Esta pesquisa é sobre a exploração infantil no trabalho, na atualidade, e procura caracterizá-la e mapeá-la por meio da elaboração de um instrumento piloto de pesquisa. A investigação foi realizada junto aos relatórios de averiguação da Delegacia Regional do Trabalho de Florianópolis, Santa Catarina, e com entrevistas semi-estruturadas feitas a 106 responsáveis imediatos pelas crianças, entre cinco e 15 anos, atendidas na emergência do Hospital Infantil Joana de Gusmão. O ponto de partida foi a análise de acidentes infantis no trabalho. Entretanto, a apreensão do fenômeno exigiu uma saída da aparência imediata do acidente. A exploração da criança ocorre em formas invisíveis, integrando o trabalho social abstrato, diferentemente do que ocorria nos primórdios da Revolução Industrial. Entre os resultados, destacamos o avanço dos prestadores de serviços, sobretudo, os domésticos.

Palavras-chave: exploração infantil no trabalho, trabalho social abstrato, trabalho ajuda.

\begin{abstract}
This research focuses on the subject of child exploration at work at the present time with a view to define it and map it out by means of a research pilot scheme. The investigation was carried out based on the reports on child exploration at work by the Labour Department of the Regional Police Service of Florianópolis, Santa Catarina, and we carried out semi-structured interviews with 106 people directly in charge of children between five and fifteen years of age taken into care at the emergency department of the Child Hospital Joana de Gusmão. We took as our starting point the analysis of child accidents at work. However, the implications of the phenomenon at the present time meant that we had to disregard the immediate circumstances of the accident. Child exploration at work at the present time is invisible and, therefore, forms part of the abstract social work, qualitatively different from those that were found at the beginning of the Industrial Revolution.
\end{abstract}

Word-key: child exploration at work, abstract social work.

\footnotetext{
${ }^{1}$ Mestre em Sociologia Política/UFSC e professora NDI/UFSC. E-mail: soraya.conde@globo.com. Agradeço à Bernardete Wrubleviski Aued pelas imprescindíveis contribuições.
} 


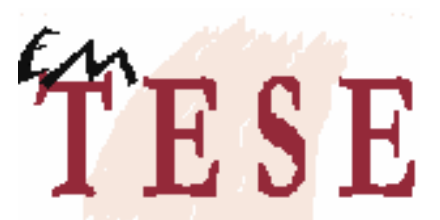

Revista Eletrônica dos Pós-Graduandos em Sociologia Política da UFSC

Vol. 4 n. 2 (2), janeiro-julho/2008

ISSN 1806-5023

\section{INTRODUÇÃO}

"Que importa do nauta o berço, Donde é filho, qual o seu lar? Amo a cadência do verso Que lhe ensina o velho mar! [...] Era um sonho Dantesco [...] O tombadilho, Que das luzernas avermelha o brilho, Em sangue a se banhar [...] Negras mulheres suspendendo as tetas Magras crianças, cujas bocas pretas Rega o sangue das mães [...] São os filhos do deserto [...] São os guerreiros ousados, Que com tigres mosqueados Combatem na solidão [...] Homens simples, fortes, bravos [...] Sem luz, sem ar, sem razão[... $]^{2}$

A compreensão das atuais formas em que ocorre a exploração infantil no trabalho, tem sido de difícil apreensão. Os nexos que a constituem escapam das relações aparentes e imediatamente perceptíveis. Além disso, há problemas teóricos, pois se para alguns autores a exploração das crianças tende a desaparecer com o progresso do capitalismo e da ampliação de suas políticas públicas; para outros, essa problemática tem assumido dimensões grandiosas e semelhantes ao "inferno dantesco", dos primórdios da era capital, conforme a descrição poética de Castro Alves n'O Navio Negreiro, citado acima.

A criança que trabalha desenvolve danos irreversíveis, física e emocionalmente, à sua formação. No entanto, estes danos não se fazem perceptíveis e para visualizá-los concorrem diversos obstáculos. De maneira geral, o trabalho da criança é visto como uma ajuda ao orçamento familiar minguado ou, ainda, como uma ação preventiva para o uso de drogas. O trabalho na fumicultura é exemplar de diversos trabalhos exercidos junto com a família. As crianças, devido à sua baixa estatura, são responsáveis pela coleta das primeiras folhas do fumo, “o baixeiro", que assegura à família renda em dinheiro após um longo tempo de investimentos na lavoura. Nesse contexto, o trabalho

\footnotetext{
${ }^{2}$ ALVES, Castro (Tragédia no Mar - O Navio Negreiro - 1869, p. 643 - 657)
} 


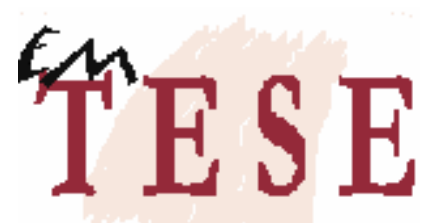

Revista Eletrônica dos Pós-Graduandos em Sociologia Política da UFSC

Vol. 4 n. 2 (2), janeiro-julho/2008

ISSN 1806-5023

infantil é defendido, também, como princípio educativo, portanto, benéfico à própria criança que deve se preparar ainda muito jovem para a inserção no trabalho. Nessa mesma linha está o trabalho tolerável, como ilustra o cultivo da maçã ${ }^{3}$. Sem nos alongarmos com a ilustração dos casos, enfatizamos que são tênues as fronteiras que estabelecem o veto à criança que trabalha, uma vez que se trata de exploração infantil. No geral, prevalece a inserção da criança como algo tolerável e, em alguns casos, até educativo. Como sugere Max Weber o trabalho não é condenável:

o trabalho constitui, antes de mais nada, a própria finalidade da vida. A expressão paulina "Quem não trabalha não deve comer" é incondicionalmente válida para todos. A falta de vontade de trabalhar é um sintoma da ausência do estado de graça (Weber, 1996, p. 113)

De acordo com a concepção apologética ao trabalho, ajudar os pais, nos diversos serviços domésticos, como por exemplo, fazer a cama, varrer a casa, dar trato aos animais ou cuidar dos irmãos não é considerada exploração infantil no trabalho. Evidentemente, nessa formulação, a referência é o trabalho enquanto uma categoria histórica, em geral, eterna necessidade humana e não o trabalho assalariado, pressuposto da acumulação capitalista, que produz valor excedente para outrem, não para si próprio.

Além da dimensão qualitativa correlata está a dimensão quantitativa. Quantas são as crianças que trabalham no Brasil? Onde elas trabalham? Segundo dados oficiais há 246 milhões de meninos e meninas trabalhando no planeta; sendo que desses cerca de três milhões estão no Brasil, com 1,48 milhão de crianças trabalhando no campo e 1,49 milhão na cidade (PNAD/IBGE/2005).

Na região Sul do Brasil, 527.951 crianças trabalham e no estado de Santa Catarina, este número é de 112.057 , o que corresponde, respectivamente, a $10 \%$ e $9,62 \%$ do total

\footnotetext{
${ }^{3}$ Conforme sugere o alvará de autorização, concedido pelo juiz Ronaldo Denardi, em São Joaquim (SC), em 2005, que libera menores de 16 anos para carregar sacos de 25 quilos e ficarem expostos à contaminação por agrotóxicos, acidentes com instrumentos cortantes, quedas de escadas, picadas de insetos e recebem cerca de $\mathrm{R} \$ 350,00$ por mês. Na autorização, o juiz defende o trabalho infantil citando, como exemplo, Visconde de Mauá, que começou a trabalhar aos nove anos de idade e ficou rico. Menciona, também, o exemplo de sua própria trajetória de trabalho iniciada aos 12 anos como chapeador. (REVISTA OBSERVATÓRIO SOCIAL, JAN/2006, p. 29).
} 


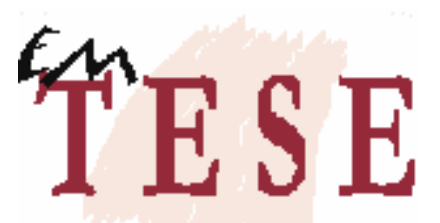

Revista Eletrônica dos Pós-Graduandos em Sociologia Política da UFSC

Vol. 4 n. 2 (2), janeiro-julho/2008

ISSN 1806-5023

da população sulista e catarinense na faixa etária entre cinco e 15 anos. (PNAD/IBGE/2005). Se no Brasil, a maior parte $(50,18 \%)$ do trabalho infantil é realizada na cidade, em Santa Catarina, esta tendência não é verificada, visto que $62,63 \%$ é efetivado por crianças e adolescentes que vivem na área rural. A maior parte destas crianças $(62,63 \%)$ não recebe remuneração uma vez que trabalham em regime familiar (PNAD/IBGE/2005).

Desde 1990 as denúncias de exploração infantil têm aumentado e delas emergiram políticas públicas que têm procurado corrigir ou minimizar os resultados da precocidade no trabalho. Todavia, os dados do governo federal brasileiro apontam que entre 1995 a 2002 houve uma redução de 41,95\% no número de crianças e adolescentes trabalhadores no país na faixa etária de cinco - 15 anos. Em termos relativos, a taxa de crianças trabalhadoras diminuiu de 13,74\%, em 1995, para 8,22\%, em 2002. (MAPA DE INDICATIVOS DO TRABALHO DA CRIANÇA E DO ADOLESCENTE NO BRASIL, 2005). Mesmo assim, o problema está longe de ser equacionado e a dimensão do mesmo parece estar subestimada.

Em termos metodológicos, a pesquisa se orientou pelos seguintes pressupostos:

- Apesar do aumento das políticas públicas à erradicação do trabalho infantil, essas não têm constituído medidas eficazes para eliminar a criança que trabalha;

- A exploração infantil no trabalho vem aumentando, mas não é visível devido aos laços sociais que a encobrem;

- As denúncias atuais de exploração infantil no trabalho não estão mais no interior das fábricas.

Segundo um diretor de fiscalização do Mistério do Trabalho e do Emprego (MTE), do Governo Federal, atualmente há um recuo na tendência de contratação de crianças entre cinco e 15 anos na grande indústria em função das pressões internacionais e da legislação ${ }^{4}$. Além disso, conforme Soares ${ }^{5}$ (apud FSP, 2005), o problema migrou para o

\footnotetext{
${ }^{4}$ É interessante notar que embora a legislação brasileira tenha proibido o trabalho de menores de 16 anos, salvo na condição de aprendiz, a mesma não prevê punições para os infratores e dirige os casos de trabalho infantil para medidas de proteção: encaminhamento aos pais ou responsáveis, orientação, apoio e
} 


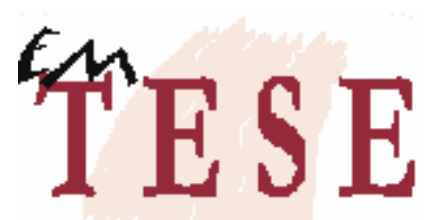

Revista Eletrônica dos Pós-Graduandos em Sociologia Política da UFSC

Vol. 4 n. 2 (2), janeiro-julho/2008

ISSN 1806-5023

"setor informal". Embora os dados do Instituto Brasileiro de Geografia e Estatísticas (IBGE) indiquem que cerca de três milhões de crianças trabalhem no país, não se sabe exatamente quantas estão trabalhando. As denúncias de fiscalização esbarram no número insuficiente de fiscais, pois o governo federal extinguiu grupos especiais de fiscalização do trabalho infantil que atuavam junto ao MTE. Todavia, esta é somente uma faceta do problema, pois outra é a questão subjacente à eficácia das políticas públicas.

\section{A PESQUISA JUNTO À DELEGACIA REGIONAL DO TRABALHO}

$\mathrm{Na}$ tentativa de localizarmos quantas, onde e como as crianças estão trabalhando no estado de Santa Catarina, realizamos uma pesquisa junto à Delegacia Regional do Trabalho (DRT/SC), responsável pela averiguação e fiscalização das condições em que as diferentes formas de trabalho ${ }^{6}$ se desenvolvem. Pesquisamos relatórios das fiscalizações ocorridas entre os anos de 2004 e $2006^{7}$. Nesse período, foram registradas 255 ocorrências de exploração infantil no trabalho. Tais registros, oriundos de atividades de fiscalização, abordagens de rua e de denúncias, referem-se à exploração de menores de 16 anos em condições insalubres, perigosas e em jornadas extenuantes, sem possibilidade de aprendizagem profissional.

Durante o ano de 2004 foram registradas 105 ocorrências de exploração do trabalho infantil no estado, onde 111 crianças foram encontradas trabalhando. No ano de 2005, foram registradas 85 ocorrências que totalizaram 106 crianças trabalhando. Até julho de

acompanhamento temporário, matrícula e freqüência obrigatória em instituições de ensino, inclusão em programa comunitário, requisição de tratamento médico, psicológico, psiquiátrico, abrigo em entidade, colocação em família substituta, inclusão em programa oficial ou comunitário de auxílio no tratamento a alcoólatras e toxicômanos.

${ }^{5}$ Diretor de Fiscalização do MTE, em entrevista concedida ao Jornal Folha de São Paulo em 10 de julho de 2005.

${ }^{6}$ Entende-se por diferentes formas de trabalho as várias maneiras, legais ou ilegais, cujo objetivo é a produção e a reprodução da existência humana.

${ }^{7} \mathrm{O}$ período das ocorrências aqui analisadas foi escolhido em virtude da inexistência de registros de fiscalização da exploração infantil nos anos anteriores. Conforme informações concedidas pela auditora fiscal C. S. F., os documentos referentes aos anos anteriores foram perdidos durante a última mudança de prédio. 


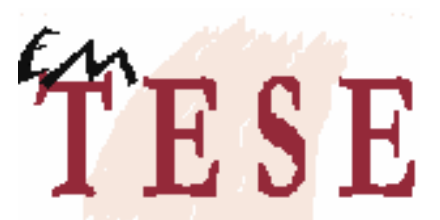

Revista Eletrônica dos Pós-Graduandos em Sociologia Política da UFSC

Vol. 4 n. 2 (2), janeiro-julho/2008

ISSN 1806-5023

$2006^{8}$ foram registradas 70 ocorrências de casos de exploração infantil no trabalho, envolvendo 92 crianças do estado de Santa Catarina. Ainda segundo esta fonte de documentação, após o flagrante de trabalho infantil, as crianças são encaminhadas ao Conselho Tutelar, para concessão de bolsas do Programa de Erradicação do Trabalho Infantil (PETI) que lhes proporciona um rendimento mensal de $\mathrm{R} \$ 40,00$ desde que a criança permaneça matriculada numa escola. Por conseguinte, são raros os casos em que se interrompe o trabalho da criança, sendo que no melhor dos exemplos, a criança passa a freqüentar a escola, num período, e, no outro, continua trabalhando. Deste modo, é questionável a eficácia dos programas políticos de erradicação.

Os municípios em que a fiscalização encontrou crianças trabalhando são:

1. Água Doce (plantação e colheita de morango com jornada de trabalho diária de dez horas e exposição constante a agrotóxicos, ao sol, ao frio e à chuva); 2. Alfredo Wagner (plantio e colheita da cebola com jornada de trabalho diária de quatro a oito horas, exposição a agrotóxicos, manipulação de instrumentos cortantes e exposição ao sol, ao frio, ao vento e a chuva; trabalho na boleia do caminhão carregando e vendendo frutas na estrada com jornada diária de trabalho indefinida e risco de acidentes na estrada); 3. Araranguá (aplicação de resíduos em fibras com jornada diária de trabalho de oito horas e exposição a cheiro forte, a produtos químicos e ao sol, ao frio, à chuva e ao vento); 4. Balneário de Camboriú (construção civil com jornada de trabalho diária de dez horas, manipulação de instrumentos cortantes e carregamento de pesos excessivos; e comércio ambulante nas praias com jornada de seis horas diárias e exposição extenuante ao sol); 5. Bombinhas (empacotamento em supermercados com jornada de trabalho de quatro horas diárias); 6. Braço do Norte (garçonete com jornada de quatro horas diárias); 7. Brunópolis (plantio, colheita e ensaque de cebola em regime familiar, ao céu aberto e com carregamento excessivo de peso); 8. Blumenau (pastelarias com jornadas diárias de seis horas e exposição a óleos quentes com risco de queimaduras); 9. Caçador (plantação de tomate e de cebola com jornada de dez horas diárias e exposição a agrotóxicos, ao sol e ao frio; viveiro de animais com jornadas de dez horas diárias em

\footnotetext{
${ }^{8}$ Período em que esta pesquisadora coletou os dados.
} 


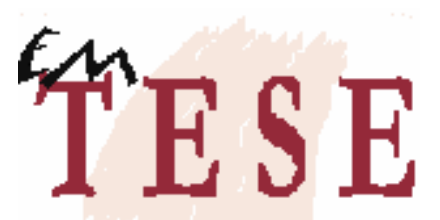

Revista Eletrônica dos Pós-Graduandos em Sociologia Política da UFSC

Vol. 4 n. 2 (2), janeiro-julho/2008

ISSN 1806-5023

locais fétidos e de condições sanitárias deploráveis; construção civil com jornadas de seis horas diárias e manipulação de instrumentos perigosos, carregamento de pesos e exposição a poeira excessiva; rebobinamento de papel higiênico, corte de pinus e enchimento de sacos de mudas de plantas a céu aberto com manipulação de instrumentos perigosos); 10. Calmon (madeireira com jornada de trabalho diária indeterminada, exposição ao pó; ao ruído e com manipulação de máquinas perigosas); 11. Canelinha (cerâmica com jornada de trabalho diário entre oito e dez horas, exposição ao pó, ao forno quente e com manipulação de máquinas perigosas; direção de tratores com jornada de oito horas diárias); 12. Chapecó (classificação de fumo com jornada de trabalho diário de 11 horas e exposição e manipulação de agrotóxicos, instrumentos cortantes ao céu aberto; serigrafia com jornada diária de oito horas, manipulação de produtos químicos nocivos e máquinas perigosas; empacotamento em supermercados; ensacamento de carvão, garçom, office boy e limpador de barcos com jornadas de oito horas de trabalho diárias e exposição constante a céu aberto; pizzaiolo com jornada diária de seis horas de trabalho e exposição constante a calor excessivo com risco de acidente em forno quente); 13. Correia Pinto (serraria com jornada diária de trabalho de oito horas e exposição ao pó, a ruídos e com manipulação de máquinas perigosas); 14. Criciúma (lavação de automóveis com jornadas diárias de trabalho indeterminadas e risco de acidente de trânsito); 15. Cunhaporã (acabamento de forro em funerária - ocorrência com dados incompletos); 16. Florianópolis (venda ambulante nas praias com jornada de trabalho diária de oito a dez horas durante a temporada de verão, expostos ao sol, ao vento e à chuva; guardadores de carros com jornadas de trabalho indeterminadas e expostas aos perigos da rua e do trânsito); 17.Gaspar (trabalho na produção de produtos químicos com jornada diária de trabalho indefinida, manipulação de solventes químicos, com más condições sanitárias e em local mal ventilado); 18. Içara (plantação de tomates com jornada de trabalho diária de oito horas por dia e exposição constantes aos agrotóxicos, ao sol, ao vento, ao frio e à chuva); 19. Irani (enchimento de tubetes para mudas de plantas ao céu aberto - ocorrência com informações incompletas); 20. Ituporanga (plantio e colheita da cebola em regime familiar de jornada de trabalho diária indeterminada com exposição aos agrotóxicos e ao 


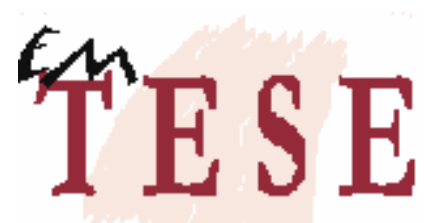

Revista Eletrônica dos Pós-Graduandos em Sociologia Política da UFSC

Vol. 4 n. 2 (2), janeiro-julho/2008

ISSN 1806-5023

sol, ao frio, à chuva e ao vento); 21. Jaguaruna (trabalho em tanques de camarão com jornadas de trabalho de oito horas expostos as constantes variações de temperaturas e sem equipamentos de proteção exigidos para atividade específica); 22. Lacerdópolis (frentistas de postos de gasolina com jornadas diárias de 8 horas, manipulação de produtos químicos perigosos e risco de atropelamento e acidentes de trânsito); 23. Lages (Balcão de padaria em regime familiar e exposição a forno quente; lavação de carros com jornada de trabalho diária de nove horas - registro incompleto sem informações sobre as condições de trabalho; plantação de fumo em regime familiar com jornadas indeterminadas e manipulação de agrotóxicos e exposição constante a céu aberto; limpeza de pestífício com jornada de quatro horas diárias e manipulação de máquinas pesadas e perigosas e produtos químicos em ambiente insalubre; empacotamento de picolés com maquinaria pesada e em local mal ventilado); 24.Monte Carlo (plantio, colheita e ensaque de cebola em regime familiar, ao céu aberto e com carregamento excessivo de peso); 25.Nova Erechim (marcenaria com jornadas de trabalho de seis horas diárias, expostos ao pó, ao ruído das máquinas e com manipulação de instrumentos perigosos); 26.Nova Trento (garçons encontrados trabalhando na hora do almoço - documento incompleto sem informações adicionais); 27. Palhoça (garçom em bar na temporada de verão - documento incompleto sem informações adicionais; construção civil com jornada de oito horas e exposição a pó, carregamento excessivo de peso, colocação de mármore e manipulação de instrumentos perigosos e cortantes; serviço de chapa $^{9}$ na Central de Abastecimento Alimentar (CEASA) com jornada de seis horas e carregamento excessivo de peso ao céu aberto); 28. Santa Helena (madeireira com jornada de trabalho diária de seis horas, exposição à pó, ruído e à máquina perigosa); 29. Santo Amaro da Imperatriz (produção de calçados com jornada de trabalho diária de quatro horas e manipulação direta e constante de cola de sapateiro); 30.São João Batista (produção de calçados com jornada de trabalho diária entre seis e dez horas em regime familiar de cotas, manipulação de cola de sapateiro e

\footnotetext{
${ }^{9}$ Conforme os relatórios da inspeção grande é o número de crianças que trabalham como "Chapas" nos CEASAS do estado de Santa Catarina. O serviço de "Chapa" consiste no carregamento de caixas de frutas, verduras e legumes dos caminhões que descarregam no Ceasa todos os dias a partir das 4 horas da manhã.
} 


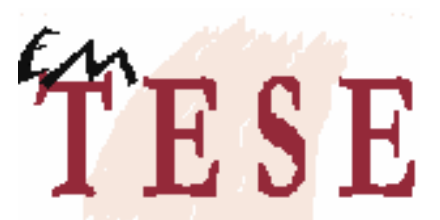

Revista Eletrônica dos Pós-Graduandos em Sociologia Política da UFSC

Vol. 4 n. 2 (2), janeiro-julho/2008

ISSN 1806-5023

de instrumentos cortantes perigosos); 31.São Joaquim (empacotamento em supermercado com jornada de trabalho diária de oito horas); 32.São José (madeireira com jornada de trabalho entre oito e dez horas, manipulação de instrumentos cortantes, máquinas perigosas e exposição ao pó da madeira; serviço de chapa no CEASA com jornada de seis horas e carregamento excessivo de peso ao céu aberto; metalurgia com manipulação de maquinaria pesada e ruídos excessivos ); 33.Tijucas (olaria com exposição ao pó e ao forno quente e manipulação de máquinas perigosas) 34.Videira (entrega e venda de jornal na rua com jornada diária de trabalho de cinco horas e exposição aos perigos da rua, do trânsito e ao céu aberto; venda de balas na rua com jornada de trabalho diária indefinida, exposição aos perigos da rua e do trânsito e ao céu aberto; trabalho na construção civil com jornada de seis a oito horas e carregamento de peso excessivo, poeira e ruídos); 35.Xanxerê (lavação de automóveis com jornada diária de trabalho indefinida realizada na rua à céu aberto e com risco de acidente de trânsito); 36.Xaxim (trabalho como chapa no Ceasa, ocorrência com dados incompletos).

Como percebemos, cenas de exploração infantil não são raras em Santa Catarina, pois dos 293 municípios do estado, 36 revelam situações de crianças que trabalham. Conforme as descrições dos relatórios, enfatizamos que o contexto não é mais taylorista/fordista, mas combina formas híbridas com diversas relações e processos de trabalho.

O espaço fabril não concentra homens, máquinas e matérias-prima As diferentes etapas do processo produtivo são desenvolvidas em locais diluídos, sendo apenas a montagem final, na maior parte dos casos, feita no chão de fábrica. Consequentemente, o trabalhador que desempenha suas funções pelas bordas da produção, não se identifica com as tradicionais formas do assalariamento e a exploração da criança é confundida com a ajuda familiar. Os sujeitos não reconhecem o produto final do próprio trabalho, realizado em espaços diluídos e, assim, não visualizavam e nem compreendem o que acontece à lata que a criança cata. A reciclagem vira o quê? A resposta a essa questão nos faz enxergar a exploração da criança como parte das atuais formas de obtenção da mais-valia. 


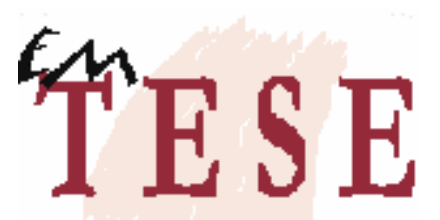

Revista Eletrônica dos Pós-Graduandos em Sociologia Política da UFSC

Vol. 4 n. 2 (2), janeiro-julho/2008

ISSN 1806-5023

Como podemos perceber, no estado de Santa Catarina, as crianças trabalham, em jornadas que variam entre quatro e 11 horas, nas seguintes atividades: extração de pedras, cerâmica, fumo, serigrafia, carvão, office boy, limpeza de barco, pizzaiolo, agricultura, aplicação de resina em fibras, construção civil, carregamento de peso, chapa, empacotamento de compras em supermercados, garçom, culinária, aviário, pestifício, rebobinamento de papel higiênico, corte de árvores, ensacamento de mudas, madeireira, lavação de carros, venda ambulante nas ruas, frente de posto de gasolina, balcão de padaria, produção de calçados e entrega e venda de jornal. Percebemos que, embora as jornadas de trabalho sejam menores do que as século XIX, muitas extrapolam às oito horas diárias regulamentadas ao trabalhador adulto.

\section{A ABORDAGEM PRECURSORA DA EXPLORAÇÃO INFANTIL NO TRABALHO}

Com a mesma delicadeza de consciência observaram os fabricantes de vidro que não era possível conceder aos meninos refeições regulares, porque se perderia, se desperdiçaria determinada quantidade de calor que os fornos irradiam. [...] Os meninos trabalham nos fornos que fazem garrafas e flint andam durante a execução de seu trabalho ininterrupto, 15 a 20 milhas inglesas em 6 horas. E o trabalho dura freqüentemente 14 a 15 horas. [...] O tempo que resta realmente para repouso é extremamente curto. Não sobra tempo para diversão, para respirar ar puro, à custa do sono tão indispensável aos meninos que executam um trabalho tão fatigante [...] Enquanto isso ocorre, talvez tarde da noite, o dono da fábrica de vidros, cheio de abstinência e de vinho do porto, sai do clube para casa, compassos incertos, cantarolando imbecilmente: britans never shall be slaves! (Nunca jamais os ingleses serão escravos!)

Childrens's Employment Comission. Fourth Report, 1865.

(MARX, 1968: 299)

A noção de exploração no trabalho e, sobretudo, infantil, advém dos estudos fundamentados em Karl Marx que se referem ao trabalho na forma assalariada e na grande fábrica desenvolvidos no final do século XVIII, em diante, na Inglaterra. Para este autor, a exploração infantil no trabalho, sinônimo de "meia força de trabalho", 


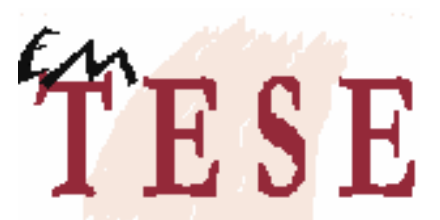

Revista Eletrônica dos Pós-Graduandos em Sociologia Política da UFSC

Vol. 4 n. 2 (2), janeiro-julho/2008

ISSN 1806-5023

explica-se desde que considerada não em si mesma, mas em relação ao contexto social que assegurou a instituição do trabalho social coletivo.

A emergência da sociedade burguesa e a incorporação da maquinaria criam condições à incorporação de crianças no trabalho industrial. Enquanto o trabalho medieval se desenvolve ao redor da casa e junto à família; na modernidade capitalista emerge a individualidade e o trabalho passa a ser realizado em locais específicos e distantes do cotidiano familiar. As crianças são coercitivamente incorporadas ao processo de trabalho fabril, junto da divisão social do trabalho e da introdução das máquinas. O homem transforma-se em mero acessório da maquinaria, os salários são comprimidos, a produção é otimizada e os trabalhadores tornam-se descartáveis.

Os resultados das transformações descritas acima e o atributo da máquina em aliviar a labuta humana, são questionados por Marx:

Tal não é também de modo algum a finalidade da maquinaria utilizada como capital. Igual a qualquer outro desenvolvimento da força produtiva do trabalho, ela se destina a baratear mercadorias e encurtar a parte da jornada de trabalho que o trabalhador precisa para si mesmo, a fim de encompridar a outra parte de sua jornada de trabalho que ele dá de graça ao capitalista. Ela é o meio de produção de maisvalia. (Marx, 1988, p. 5)

A introdução da iluminação nas fábricas realizadas primeiramente à gás, por exemplo, alonga a jornada de trabalho e permite crianças e mulheres trabalharem à noite. O dispenso da força muscular, assegura a apropriação do trabalho de crianças e de mulheres, aumenta o número de assalariados e confere a todos os membros familiares a qualidade de trabalhadores produtivos, sem limitações legais ou humanas à exploração. Neste sentido, Marx analisa anúncios de contrato que chamavam meninos e meninas de 12 anos para trabalharem desde que tivessem aparência de mais de 13:

crianças com menos de 13 anos só podem trabalhar seis horas. Um médico [...] tem que atestar a idade. O fabricante pede jovens que aparentem já ter 13 anos. [...] No mal-afamado distrito londrino de Bethnal Green, a cada segunda e terça-feira pela manhã, é realizado um mercado público, em que crianças de ambos os sexos, a partir dos 9 anos de idade, alugam a si mesmas para manufaturas de seda londrinas [...] os contratos são 


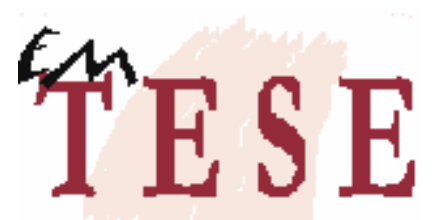

Revista Eletrônica dos Pós-Graduandos em Sociologia Política da UFSC

Vol. 4 n. 2 (2), janeiro-julho/2008

ISSN 1806-5023

válidos por uma semana [...] Apesar da legislação, pelo menos 2 mil jovens continuam sendo vendidos por seus próprios pais como máquinas vivas para limpar chaminés [...] Toda vez que a lei fabril limita a seis horas o trabalho infantil em ramos industriais até então não atingidos, ecoa sempre de novo a lamentação dos fabricantes: que parte dos pais retiraria as crianças da indústria agora regulamentada, para vendê-las naquelas onde ainda predomina ä liberdade de trabalho, isto é, onde crianças com menos de 13 anos são obrigadas a trabalhar como adultos, podendo, portanto,serem alienadas a um preço maior (Marx, 1988,p. 22)

Mas, segundo este autor, ainda no século XIX emergiram medidas que impuseram limite à voracidade do capital, principalmente em alguns ramos da atividade econômica enquanto que noutros não havia o que restringisse à exploração da força de trabalho, como sugere o relatório:

Para nosso estudo basta extrair alguns depoimentos de crianças exploradas, encontradas nos relatórios de 1860 e 1863. Pelo que ocorre com as crianças pode-se deduzir o que se passa com os adultos, principalmente meninas e senhoras, numa indústria ao lado da qual a fiação de algodão e outras atividades semelhantes pareceriam agradáveis e sadias. Wilhelm Wood, um garoto de nove anos, "tinha sete anos e 10 meses de idade, quando começou a trabalhar". Lidava com fôrmas (levava a mercadoria à câmara de secagem para apanhar depois, de volta, as fôrmas vazias) desde o início. Chega, todo dia da semana, no trabalho, às 6 horas da manhã e acaba sua jornada por volta de 9 horas da noite. "Trabalho até á 9 horas da noite, todo dia da semana. Assim, por exemplo, durante as últimas 7 a 8 semanas". Quinze horas de trabalho por dia para um garoto de sete anos! J. Murray, um menino de 12 anos depõe: "Lido com fôrmas e faço girar a roda. Chego ao trabalho às 6 horas da manhã, às vezes às 4. Trabalhei a noite toda passada, indo até às 6 horas da manhã. Não durmo desde a noite passada. Havia ainda oito ou nove garotos que trabalhavam durante toda a noite passada. Todos menos um voltaram esta manhã. Recebo por semana 3 xelins e 6 pence. Nada recebo a mais por trabalhar a noite. Na semana passada trabalhei 2 noites (Marx, 1968p. 276-7). 


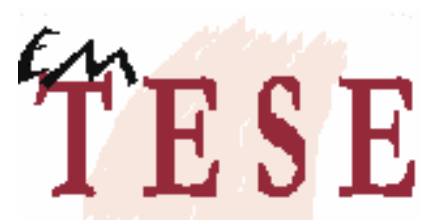

Revista Eletrônica dos Pós-Graduandos em Sociologia Política da UFSC

Vol. 4 n. 2 (2), janeiro-julho/2008

ISSN 1806-5023

As longas horas de trabalho são evidencias constatadas entre o trabalho infantil acrescentadas da deterioração das condições de trabalho.

A fabricação de fósforos de atrito data de 1833, quando se inventou o processo de aplicar o fósforo ao palito de madeira. Desde 1845 desenvolveu-se rapidamente na Inglaterra, espalhando-se das zonas mais populosas de Londres, para Manchester, Birmingham, Liverpool, Bristol, Norwich, Newcastle e Glasgow e com ela floresceu o trismo, que segundo descoberta de um médico de Viena já em 1845, é doença peculiar dos trabalhadores dessa indústria. A metade dos trabalhadores são meninos com menos de 13 anos e adolescentes com menos de 18. Essa indústria é tão insalubre, repugnante e mal afamada que somente a parte mais miserável da classe trabalhadores, viúvas famintas, etc., cede-lhe seus filhos, "Crianças esfarrapadas, subnutridas, sem nunca terem freqüentado a escola. Entre as testemunhas inquiridas pelo comissário White (1863), 270 tinham menos de 18 anos, 40 menos de 10, 10 apenas oito e cinco apenas seis. $O$ dia de trabalho variava entre 12, 14 e 15 horas, com trabalho noturno, refeições irregulares, em regra no próprio local de trabalho, empestado pelo fósforo. Dante acharia que foram ultrapassadas nessa indústria suas mais cruéis fantasias infernais. (Marx, 1968,p. 278).

Os estudos de Marx apontam para a exploração infantil no trabalho no interior das fábricas na primeira metade do século XIX. Essa parece ser uma das diferenças de seus estudos em relação à atualidade. Deixamos para trás as cenas dantescas do século XIX? "A vida era dura naquele tempo, mas voltamos coletivamente à razão e fizemos um mundo que Marx com certeza nunca iria reconhecer”. (Harvey, 2004,p. 21).

Contrariando as perspectivas otimistas em relação ao progresso capitalista da humanidade, enfatizamos os resultados da pesquisa realizada junto aos relatórios de inspeção da DRT descritos anteriormente e, sobretudo, os depoimentos das famílias das crianças atendidas pela emergência do HIJG, a seguir. 


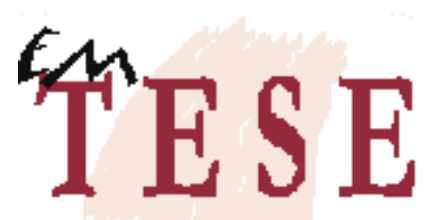

Revista Eletrônica dos Pós-Graduandos em Sociologia Política da UFSC

Vol. 4 n. 2 (2), janeiro-julho/2008

ISSN 1806-5023

\section{A EXPLORAÇÃO INFANTIL NO TRABALHO, SEGUNDO OS ATENDIMENTOS DA EMERGÊNCIA DO HIJG ${ }^{10}$}

A exploração infantil, na atualidade, vem assumindo formas específicas e ocultadas por relações que a transformam numa necessidade contemporânea. Para os pais das crianças trabalhadoras que, em geral, são de baixa renda, esse assunto é proibido. A criança "ajuda" à família e é, por meio dessa, educada.

Para conferir visibilidade ao que denominamos trabalho e a família insiste em chamar de ajuda, sistematizamos uma metodologia fundamentada no aporte sociológico, o que significa ir além da manifestação aparente e perceber a criança no contexto das relações sociais em que está situada. Cientes das maneiras de ocultação do caráter de exploração da criança, selecionamos procedimentos metodológicos que consistiram em:

- Apreender, por meio de entrevistas, o contexto que deu origem ao motivo de procura de uma emergência hospitalar (“o que aconteceu com a criança?”)

- Dimensionar o que a criança faz quando não está na escola (o que ela faz no período oposta à escola? O que ela faz a noite? O que ela faz nos finais de semana?);

- Qualificar a inserção da criança no trabalho (Quais atividades desempenhadas pela criança? Descrição da consistência das atividades desenvolvidas. Com que freqüência ela executa a tarefa? Em quais horários? Onde? Como? Por quê? Para quê?);

- Caracterizar o contexto sócio-econômico e familiar (Qual a profissão dos responsáveis? Qual a renda familiar? Em que bairro reside? Em que tipo de moradia? Com quem mora em casa? Quantos irmãos, o que fazem e quais as idades? Recebe algum tipo de bolsa do governo federal?).

Neste sentido, procuramos dimensionar o problema da exploração infantil no trabalho tomando por referência as manifestações e evidências de trabalho de criança. $O$ ponto de partida deste estudo deu-se na emergência do Hospital Infantil Joana de Gusmão, em Florianópolis, SC. Entretanto, o que parecia simples revelou-se muito

\footnotetext{
${ }^{10}$ Hospital Infantil Joana de Gusmão
} 


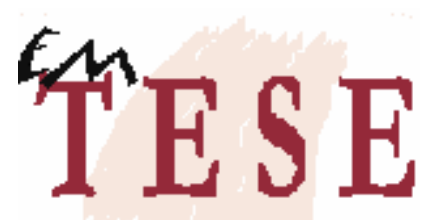

Revista Eletrônica dos Pós-Graduandos em Sociologia Política da UFSC

Vol. 4 n. 2 (2), janeiro-julho/2008

ISSN 1806-5023

difícil. Trabalho infantil, assim como acidente de trabalho, é assunto proibido. ${ }^{11}$ Os atendimentos mais solicitados, no período da pesquisa, foram referentes à febre (3.959); dor (259) e procedimentos microcirurgicos e ortopédicos (319). Que fazer com tão grandes dimensões do atendimento? Constatando a ausência de uma base de dados sobre trabalho infantil e pela exigüidade de recursos, optamos por uma investigação preliminar estabelecendo um plano piloto que privilegia a dimensão qualitativa.

Da população atendida, entre os dias 15 e 30 de setembro de 2006, foram realizadas 106 entrevistas com as famílias que procuraram atendimento na emergência externa do hospital infantil. Das 106 famílias, 70 procuraram atendimentos clínicos para resfriados, febres, dores de barriga, gripes, demais viroses e outras doenças infantis; 16 procuraram atendimentos cirúrgicos para cortes, fissuras, retiradas de corpos estranhos, queimaduras e acidentes; e 19 para atendimentos ortopédicos como quedas, fraturas, torções entre outros acidentes.

Em relação à procedência da população atendida, 22,28\% são oriundos de Florianópolis, 11,97\% de São José, 7,98\% de Palhoça, 3,44\% de Biguaçu e 53,51\% de outros municípios do estado de Santa Catarina. Percebemos, assim, que o HIJG é uma referência estadual em termos de atendimentos e tratamentos de doenças com gravidade pequena, média e grande e completa rede de atendimentos especializados.

As crianças entrevistadas possuem idades variadas, sendo que das 106, 35 tinham entre oito e 11 anos; 28 entre zero e três anos; 25 entre quatro e sete anos e 17 entre 12 e 16 anos. A maior parte das crianças analisadas encontra-se nas séries iniciais (37\%) e nas séries finais $(30 \%)$ do ensino fundamental. A maioria mora em casa com mãe, pai e irmãos (54\%).

\footnotetext{
${ }^{11}$ A primeira barreira enfrentada deu-se no momento em que solicitamos autorização de pesquisa junto aos membros da Comissão de Ética em Pesquisa (CEP) do Hospital. De imediato eles nos alertaram para uma possível inviabilidade da pesquisa em virtude da dinâmica intensa e movimentada da emergência pediátrica dentro do hospital. A rotina emergencial do HIJG atende entre 130 e 400 pessoas por dia. Entre os dias de realização de nossa pesquisa, 15 e 30 de setembro de 2006, foram atendidas 4.663 crianças, 1.782 a mais que no mesmo período do ano anterior, no setor de emergência, procedentes de quase todas as cidades do estado de Santa Catarina.
} 


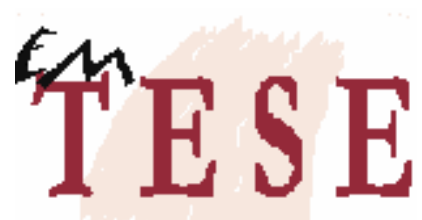

Revista Eletrônica dos Pós-Graduandos em Sociologia Política da UFSC

Vol. 4 n. 2 (2), janeiro-julho/2008

ISSN 1806-5023

Iniciamos a pesquisa fazendo um plantão diário, em turnos variados, junto ao protocolo geral da emergência do hospital. De início, descartamos os atendimentos de febre, gripe e mal estar de bebês e crianças bem pequenas, mas na medida em que a pesquisa avançou esse procedimento foi revisto.

Como exemplo da necessidade de revisão dos procedimentos de pesquisa, evidenciamos o momento em que duas adolescentes entram na emergência do hospital acompanhadas de um menino de oito anos e de um bebê de um mês. Os motivos da procura de atendimento são febre e gripe. Ao nos aproximarmos, para a realização da entrevista, a menina-mãe sorri e conta parte de sua vida:

\footnotetext{
Meu irmão tem oito anos e está com febre. Eu tenho 14 anos, mas já tenho um filho. Este é meu irmão, está na segunda série e eu não estudo mais [...] Tenho sete irmãos. Meu pai é pedreiro e minha mãe é faxineira [...] Eu também faço faxina na casa das pessoas. Meu irmão é ótimo aluno e cata latas na rua para vender junto com meu outro irmão mais novo [...]

Essa minha queimadura no rosto? Aconteceu quando eu ainda tinha seis anos. A conta de energia elétrica da minha casa tinha sido cortada. Meu pai fez uma lamparina de querosene e quando ele foi botar encima do fogão, para iluminar a cozinha, pois queria esquentar a água, um de meus irmãos passou correndo e bateu na lamparina e o óleo caiu no meu pescoço, no peito e no braço pegando fogo $[\ldots]$

Essa minha irmã? Ela tem 16 anos e tem esse bebê de um mês que está com febre [...] Ela estudou até a $7^{\mathrm{a}}$ série e abandonou a escola, pois ficou grávida. Ela trabalha com a mãe, na faxina. Meus outros irmãos mais velhos ajudam o pai que é pedreiro. Ainda tenho outra irmã que também faz faxina.

Com dinheiro recebido ajudamos a pagar as contas da casa e, às vezes, compramos uma roupinha
}

Foi em depoimentos como o acima citado, que apreendemos a necessidade de revisão dos procedimentos metodológicos. Não conseguimos identificar nenhum caso de acidente de trabalho infantil. A exceção deu-se apenas com o relato de um médico plantonista que nos disse ter atendido, recentemente, uma criança, às duas horas da madrugada, em virtude de uma bala perdida. Onde estava essa criança? Segundo o plantonista, ela guardava carros nas proximidades de uma pizzaria no bairro da Trindade, em Florianópolis.

Percebemos, então, que a criança que trabalha chega ao hospital acompanhando seus irmãos e procura atendimento para doenças típicas infantis. Portanto, o trabalho da

\footnotetext{
${ }^{12}$ Entrevistas com familiares da criança 4, concedidas às autoras entre 15 e 30 de setembro de 2006. De acordo com as exigências da Comissão de Ética do HIJG, optou-se por atribuir número à criança cuja família prestou depoimento de modo a garantir a não identificação das crianças.
} 


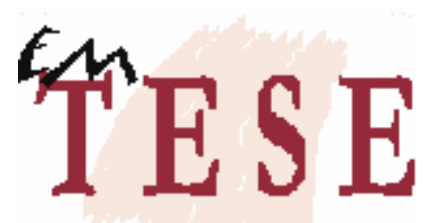

Revista Eletrônica dos Pós-Graduandos em Sociologia Política da UFSC

Vol. 4 n. 2 (2), janeiro-julho/2008

ISSN 1806-5023

criança encontra-se entranhado na vida cotidiana de determinados segmentos da população sendo, por sua vez, percebido como natural.

O trabalho infantil não ocorre isoladamente e para visualizá-lo é preciso apreender as relações em que está inserido, relacionando o que é imediatamente perceptível (o motivo de procura do atendimento) com as relações que o engendra (as condições de vida familiar). De acordo com os dados coletados, a manifestação aparente de acidente ou de doença é apenas a ponta de um imenso "iceberg", pois a patologia infantil não está descolada das condições de vida e esta, muitas vezes, é quem determina aquela. De que adianta um remédio para coceira, se ao voltar para casa, a criança continuará catando lixo todos os dias, pois é da venda do lixo que ela, sua mãe e seus cinco irmãos sobrevivem?

A segunda constatação relevante foi apreendida no momento em que perguntamos se a criança trabalha. A resposta imediata era sempre a negação do trabalho infantil. E nesse aspecto o procedimento também foi revisto passando a indagar o mesmo conteúdo, porém de forma indireta. Percebemos que o questionamento direto funcionava como um alerta para o acompanhante familiar dar a resposta negativa. A criança não trabalha, mas apenas “ajuda” a mãe a catar lixo no período oposto à escola. Para apreender esta ordem de relações indagamos sobre o que a criança faz no período em que não está na escola, qual o contexto familiar, a vida da criança, suas atividades de rotina na casa e na escola, o bairro, a profissão dos pais, a idade. Percebemos que na atualidade a exploração infantil no trabalho ocorre em espaços de serviços em geral e, principalmente, nos domésticos como ilustra a síntese da entrevista a seguir ${ }^{13}$ :

\footnotetext{
Ele pegou bicho de pé no quintal de casa. Lá em casa tem muito. Ele está com quatro bichos bem inflamados no mesmo pé. [...] Ele não gosta de estudar muito não, mas é um excelente ajudante. É meu braço direito em casa. Cuida das irmãs, vai à escola pela manhã, leva e busca as irmãs na escola, chega da escola, esquenta a comida, dá almoço, lava a louça, limpa o quintal, limpa a sujeira dos cachorros, varre a casa e arruma os quartos. Faz tudo o que precisamos até minha esposa chegar [...] Minha esposa faz faxina todos os dias até às 17 horas e eu sou pedreiro[...] Depois disso ele pode brincar. Ele gosta mesmo é de jogar bola.

No final de semana ele faz as tarefas da escola e as outras coisas da casa[...]
}

\footnotetext{
${ }^{13}$ Durante a coleta desse depoimento, a pesquisadora fez as seguintes anotações no caderno de campo: "[...] um adolescente entra com seu pai e manca da perna direita. Veste trajes adultos, com camisa social azul turquesa abotoada até o pescoço. À pergunta sobre o que aconteceu, o pai responde que a solicitação se deve ao menino estar com bicho de pé [...]"
} 


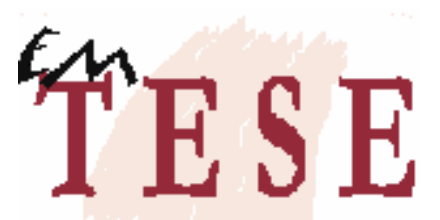

Revista Eletrônica dos Pós-Graduandos em Sociologia Política da UFSC

Vol. 4 n. 2 (2), janeiro-julho/2008

ISSN 1806-5023

Quando aparece alguma coisa que dá para o menino fazer e minha esposa está sem faxina, eu o levo para me ajudar ${ }^{14}$

Por meio da constatação de situações como essa é que percebemos a importância de desvelar os véus sociais que encobrem a exploração infantil no trabalho que, na atualidade, encontra-se disperso nas mais variadas formas de trabalho.

Prosseguindo nas indagações indiretas perguntamos o que o irmão faz quando ele não está na escola e obtivemos resultados significativos, pois $78 \%$ das crianças abordadas têm irmãos trabalhadores e/ou trabalhador-ajudante. Em termos relativos, identificamos $32 \%$ de irmãos que trabalham em caráter de ajuda sistemática nas tarefas da casa, cuidando de outros irmãos ou de outras crianças, ajudando na roça ou no trabalho dos pais e $15 \%$ de irmãos trabalhadores do comércio, da rua, da limpeza, da construção civil e da coleta de materiais recicláveis. Dos $15 \%$ de irmãos trabalhadores do comércio, dois casos estão no comércio de drogas nos morros da região central de Florianópolis e um na produção e no comércio de calçados do município de São João Batista, Santa Catarina.

A exploração infantil no trabalho tem inúmeros véus. A criança não sofre acidente de trabalho, pois este é visto como salutar ajuda. Assim, quando se pergunta o que a criança faz enquanto não está na escola, o que era imperceptível ganha notoriedade. A criança não está mais na fábrica ou na indústria, ela está nas ruas, no morro e em casa espaços de difícil averiguação. Ela vende mercadorias, lava, passa, cozinha, limpa e cuida das crianças mais novas. Nesta pesquisa, foram identificados contextos em que a criança é a única responsável pelo trabalho geral da casa, do cuidado de irmãos, de outra criança, de auxílio no trabalho não doméstico junto aos pais, e ainda, em serviços de limpeza, de construção civil e na coleta de materiais recicláveis. Estas formas de trabalho não se apresentam de imediato, como assalariada, o que poderia nos levar a concluir que não é trabalho. Entretanto, imaginemos se estes trabalhos fossem exercidos

\footnotetext{
${ }^{14}$ Entrevista concedida com o pai da criança 1 , de 13 anos, da $3^{\text {a }}$ série do ensino fundamental. Fonte: entrevistas concedidas às autoras entre 15 e 30 de setembro de 2006.
} 


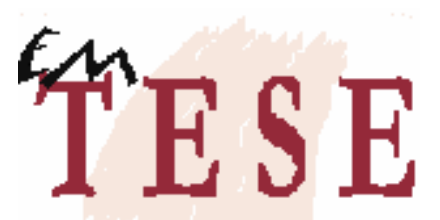

Revista Eletrônica dos Pós-Graduandos em Sociologia Política da UFSC

Vol. 4 n. 2 (2), janeiro-julho/2008

ISSN 1806-5023

por babás e faxineiras que recebessem remuneração, qual deveria ser o salário do pai ou da mãe que provê o sustento familiar?

Ilustrações são feitas com o exemplo a seguir, onde uma mãe se manifesta inconformada com o fato do filho apresentar fratura oriunda de um jogo de futebol, no domingo:

\footnotetext{
Agora estou perdida, ele é quem cuida da roupa, da louça e da comida da casa. É meu braço direito. Todos os dias ele tem que chegar da escola, fazer as tarefas da casa e depois estudar. Só o libero para brincar durante os finais de semana. Agora estou muito preocupada, pois quem vai fazer o serviço da casa? Além de não me ajudar, ele ainda me dará trabalho e gastos ${ }^{15}$
}

A irmã do garoto fraturado, que chora durante a entrevista, complementa o depoimento da mãe dizendo que não pode encontrar os amigos para jogar bola. A mãe diz: "Não liga não, ela é mal humorada mesmo! Fazer o quê se a gente tem que trabalhar?" (Fonte: entrevistas concedidas as autoras entre 15 e 30 de setembro de 2006).

Segundo o IBGE (PNAD 2001), o Brasil possui 494.002 crianças e adolescentes entre cinco e 17 anos que trabalham como domésticas e, na sua maioria, são entendidas como ajudantes. O trabalho infantil doméstico é apenas uma das manifestações da exploração da criança, resultante da condição sócio-econômica precária da família que não pode pagar serviços de uma empregada doméstica, de creche ou de babá, enquanto o responsável trabalha fora.

Situações exemplares de precarização no trabalho não são raras. Entrevistamos uma mãe que procura atendimento para a filha de nove anos com coceira e feridas pelo $\operatorname{corpo}^{16}$ :

\footnotetext{
${ }^{15}$ Entrevistas concedida pela mãe da criança 5 às autoras entre 15 e 30 de setembro de 2006.

${ }^{16}$ Antes da coleta do depoimento, foram registradas as seguintes observações pela pesquisadora: [...] a mãe, rodeada de cinco filhos pequenos, quando entra na emergência solicita água, afirmando ter andado a pé, do terminal de ônibus do centro da cidade até o HIJG, com todas as crianças. As crianças reclamam de fome e de sede. Eram 12:15hs e elas não haviam almoçado. Teriam tomado café? A mãe diz que após o regresso, igualmente a pé, deveria fazer uma fogueira para preparar a comida, já que o gás de cozinha havia acabado há alguns dias.
} 


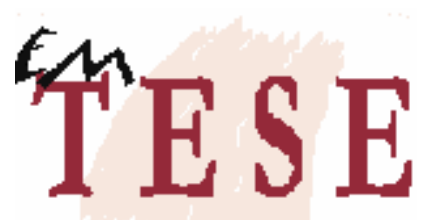

Revista Eletrônica dos Pós-Graduandos em Sociologia Política da UFSC

Vol. 4 n. 2 (2), janeiro-julho/2008

ISSN 1806-5023

\begin{abstract}
Eu tenho estes cinco filhos, além de um menino de 13 anos que está com a avó no Paraná. Ele mora com minha mãe porque eu não consegui criá-lo. Morro de saudade dele. Minha mãe diz que ele é bom, pois estuda de dia e de noite trabalha cuidando de carros no centro da cidade de Clevelândia, no Paraná. Eu não me lembro em que série da escola ele está.
\end{abstract}

Para sustentar essas crianças eu coleto lixos recicláveis na rua. Levo sempre meus cinco filhos comigo[...]

A menina mais velha, de nove anos, cata lixo e também limpa a casa, é um brilho só.

No ano passado eu juntei um dinheiro e consegui comprar um carro para a coleta de recicláveis. Encho cinco carros por dia: três durante a manhã, com ajuda das crianças e apenas dois à tarde quando fico sozinha, pois elas vão à escola. O Conselho Tutelar vive me dando bronca porque as crianças andam comigo na rua. Mas, tem escola o dia todo? E depois se nós não trabalharmos, passaremos fome. Eu recebo cerca de R $\$ 130,00$ por mês com a venda de recicláveis. Recebo, também, duas bolsas do PETI

Há 15 dias estou sem gás de cozinha e todo dia tenho que fazer fogueira para cozinhar. Consegui juntar $\mathrm{R} \$ 10,00$, mas faltam $\mathrm{R} \$ 25,00$. Por isso, vim até aqui a pé com as crianças. Os pais delas não me ajudam em nada [...]

Esse meu filho tem sete anos, aos seis sofreu queimadura enquanto eu esquentava água. Estava frio e as crianças sentaram-se perto do fogo. Ele queimou a mão tentando pegar feijão para comer $[\ldots]$

Eles morrem de vontade de terem brinquedos das lojas bonitas, mas temos que nos contentarmos com o que achamos no lixo. Não consigo nem comprar roupas. Cada mês eu compro uma co isa para um: uma escova de dente, um tênis, uma calça. Não dá para comprar para todos no mesmo mês. O ano passado ganhei uma televisão e uma geladeira no programa do César Souza. Recebo também doação de vizinhos e de conhecidos [...]

Tenho muita vontade de trazer meu filho mais velho (choro). Mas, ele é adolescente e o bairro que moramos, Aparecida de Coqueiros tem muita droga, traficante e tiroteio. Tenho medo que ele se envolva. Não os deixo sozinhos em casa. Vamos todos juntos, aonde eu vou, vamos os cinco juntos. Já tive quatro maridos, tive filho com todos e nunca mais quero casar para não ter que ficar cuidando, sozinha, dos filhos (choro). ${ }^{17}$

A manifestação de coceira em uma das crianças foi o pretexto de entrada ao hospital, entretanto, ele escamoteia as condições em que os materiais recicláveis são coletados. O que adianta receitar uma pomada, se ao voltar para casa, a criança continuará catando latas e mexendo com lixo? Evidenciamos, portanto, a criança em seu contexto e a necessidade de uma leitura sociológica dos atendimentos hospitalares. Para os médicos plantonistas, a relação entre a coceira e o trabalho não existe; já para o pesquisador social ela só existirá se ele conseguir descobrir que, embora a criança afirme que não trabalha, no período oposto à escola ela "ajuda" sua mãe a encher cinco carros de lixo reciclável. Ao contrário de grande parte das pesquisas atuais, a essência da exploração das crianças está na materialidade das relações sociais.

\footnotetext{
${ }^{17}$ Entrevista concedida pela Mãe da Criança 7 às autoras entre 15 e 30 de setembro de 2006.
} 


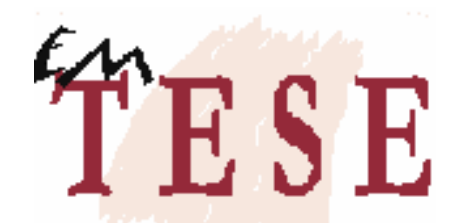

Revista Eletrônica dos Pós-Graduandos em Sociologia Política da UFSC

Vol. 4 n. 2 (2), janeiro-julho/2008

ISSN 1806-5023

A redução dos focos concentradores de crianças que trabalham - as exemplares grandes indústrias do século XIX - coincidem com o aumento da exploração em espaços ilícitos, pulverizados e de difícil visualização, onde se encontram as crianças que trabalham ao tráfico de drogas. $\mathrm{O}$ fenômeno, até então conhecido como próprio de morros cariocas, apresenta-se, também em Florianópolis, que têm vivenciado o aumento da população e o inchamento das favelas, conforme vemos no depoimento a seguir:

\footnotetext{
Eu me separei porque meu primeiro marido me batia tanto. Batia em mim e nas minhas crianças Sofri muito. Um dia, meus vizinhos chamaram a polícia e então eu me separei [...].

No início os meninos mais velhos ficaram com o pai. Até que descobri que os três trabalhavam para o tráfico de drogas. Eles tinham arma, pulavam o muro da escola todos os dias. Eles moravam com o pai no Morro da Caixa. Fiquei doida e levei os dois mais velhos para morarem com meu pai, em Lages. Meu pai é agricultor e planta fumo. Os meninos estão trabalhando com ele. Por enquanto, não vão mais à escola, pois é muito longe. Meu ex-marido é faxineiro da polícia militar. Minha vida é muito difícil. ${ }^{18}$
}

Conforme o relatório publicado pela ANDI/ março de 2005, cerca de seis mil crianças e adolescentes vivem sob o risco iminente de morte, pois trabalham no tráfico de drogas. As crianças são preferidas porque têm coragem e agilidade junto às armas de fogo, fuzis, metralhadoras, pistolas e granadas. Elas lutam contra a polícia e contra facções rivais, sem temor em relação às conseqüências. O tráfico de drogas é um ramo extremamente lucrativo, pois não paga imposto sobre a mercadoria, nem os direitos trabalhistas de seus empregados e o valor final, agregado ao produto, chega à mais de $1000 \%$.

\section{CONSIDERAÇÕES FINAIS}

A apreensão da exploração infantil no trabalho e a sua caracterização exigem uma investigação sociológica que, diferentemente de estudos quantitativos realizados por organizações governamentais e não-governamentais, usa o recurso metodológico para sair da aparência imediata e considerar a criança em suas relações sociais. Assim, durante a pesquisa de campo e a elaboração do instrumento piloto de pesquisa, não

\footnotetext{
${ }^{18}$ Entrevista concedida pela mãe da criança 8 às autoras entre 15 e 30 de setembro de 2006.
} 


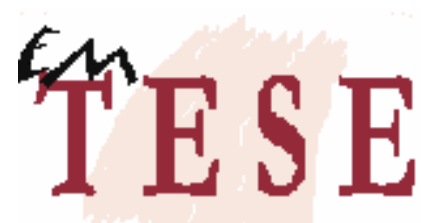

Revista Eletrônica dos Pós-Graduandos em Sociologia Política da UFSC

Vol. 4 n. 2 (2), janeiro-julho/2008

ISSN 1806-5023

alcançamos nossos objetivos perguntando diretamente por ele, mas investigando a rotina e o contexto familiar. A mudança do foco, que se descolou do cotidiano aparente e imediato, permitiu à nossa investigação dar uma guinada. Passamos, portanto, a estabelecer relações entre as necessidades da família, a rotina, a ajuda e a exploração no trabalho.

Tendo em vista a elaboração do plano piloto de pesquisa, indicamos algumas considerações sobre os aspectos mais importantes na apreensão da realidade. A exploração infantil no trabalho, na atualidade, é escamoteada em "ajuda" e difere do trabalho fabril, realizado nos espaços concentrados atestados por Marx e Engels, no século XIX. A criança trabalha na rua, no serviço doméstico, na agricultura, na venda de drogas e na venda do corpo, compondo o trabalho coletivo. A dificuldade encontrada para coletar esses dados reflete a invisibilidade do trabalho social abstrato, num estranhamento individual, coletivo e material.

Como podemos perceber, por meio dos relatórios da DRT, no estado de Santa Catarina, as crianças trabalham, em jornadas variadas entre quatro e 11 horas, nas seguintes atividades: extração de pedras, cerâmica, fumo, serigrafia, carvão, office boy, limpeza de barco, pizzaiolo, agricultura, aplicação de resina em fibras, construção civil, carregamento de peso, chapa, empacotamento de compras em supermercados, garçom, culinária, aviário, pastifício, rebobinamento de papel higiênico, corte de árvores, ensacamento de mudas, madeireira, lavação de carros, venda ambulante nas ruas, frente de posto de gasolina, balcão de padaria, produção de calçados e entrega e venda de jornal. Enfatizamos que, embora as jornadas de trabalho sejam menores do que as século XIX, muitas extrapolam as oito horas diárias regulamentadas ao trabalhador adulto.

Finalmente, para prosseguir, indicamos algumas questões que devem ser agregadas ao estudo sobre as condições em que estão ocorrendo o trabalho infantil: quantas horas as crianças estão trabalhando na atualidade? Quantas descansam? Quantas têm de lazer? Quantas horas os pais trabalham? Quantas descansam? Quantas têm de lazer? Por que a legislação coíbe o trabalho infantil, em alguns ramos da atividade econômica, enquanto 


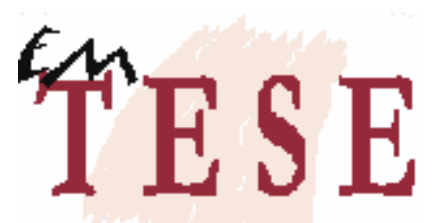

Revista Eletrônica dos Pós-Graduandos em Sociologia Política da UFSC

Vol. 4 n. 2 (2), janeiro-julho/2008

ISSN 1806-5023

que permite noutras? Se é possível, como verificamos, dizer que a jornada de trabalho das crianças diminuiu, questionamos se essa diminuição implica no aumento do tempo da criança destinado ao ócio, ao lazer e à brincadeira.

\section{Referências Bibliográficas}

AMARAL, Carlos. A evolução do trabalho infantil no Brasil de 1999 a 2001. Artigo disponível em www.andi.org.br .Acesso em 6 de outubro de 2005 às 15:45 hs.

ANTUNES, Ricardo. "Os caminhos da liofilização organizacional: as formas diferenciadas da reestruturação produtiva no Brasil". In: Idéias (Revista do Instituto de Filosofia e Ciências Humanas/UNICAMP), ano 9 (2) - 10(1). Campinas, SP: IFCH/UNICAMP. 2003. (p. 13-24)

. Os Sentidos do Trabalho: ensaio sobre a afirmação e negação do trabalho. São Paulo: Boitempo editorial São Paulo. 2005 a. $7^{\mathrm{a}}$ edição.

AUED, Bernardete W. Desemprego e Informalização. Artigo no prelo. UFSC. 2005.

CONDE, Soraya F. Trabalho Invisível. Florianópolis, SC. 2007. Dissertação (mestrado em Sociologia Política). Programa de Pós-graduação em Sociologia Política/CFH. Universidade Federal de Santa Catarina.

FOLHA DE SÃO PAULO. "Trabalho infantil migra para o quintal”. In: Folha de São Paulo/ Caderno Cotidiano. São Paulo: domingo, 10 de julho de 2005.

HARVEY, David. Espaços de esperança. São Paulo, Loyola, 2004.

BRASIL, Ministério do Trabalho e do Emprego. Mapa de Indicativos do Trabalho da Criança e do Adolescente no Brasil. $1^{\text {a }}$ edição. Brasília: MTE. 2005.

MARX. Karl. O Capital: o processo de produção do capital. (Volume 1 Livro primeiro Tomo 1). São Paulo: Nova Cultural. 1988a.

O Capital: o processo de produção do capital. (Volume 1 Livro primeiro Tomo

2). São Paulo: Nova Cultural. 1988b.

. O capital. Rio de Janeiro, Civilização Brasileira, 1968. 


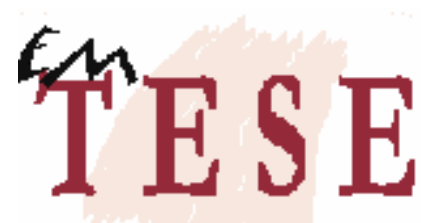

Revista Eletrônica dos Pós-Graduandos em Sociologia Política da UFSC

Vol. 4 n. 2 (2), janeiro-julho/2008

ISSN 1806-5023

NAVARRO, Vera. L. "A reestruturação produtiva na indústria de calçados de couro em Franca/SP”. In: Idéias (Revista do Instituto de Filosofia e Ciências Humanas/UNICAMP), ano 9 (2) - 10(1). Campinas, SP: IFCH/UNICAMP. 2003. (p. $113-174)$.

INSTITUTO OBSERVATÓRIO SOCIAL. " A idade da pedra: um ano depois". In: Revista Observatório Social. Instituto Observatório Social, SP, nº 9, jan. 2006.

SILVA, Maurício R. da. Trama Doce-Amarga (exploração do) Trabalho Infantil e Cultura Lúdica. São Paulo: Hucitec: 2003.

SILVA, Reginaldo de S. O processo educativo de crianças trabalhadoras na rua. São Carlos, SP. 1997. Tese (doutorado em educação): UFSCAR/Centro de Educação e Ciências Humanas. Universidade Federal de São Carlos.

WEBER, Max. A ética protestante e o espírito do capitalismo. São Paulo, Pioneira, 1996.

\section{Sites consultados:}

www.andi.org.br/tid/principal Acesso em 25/9/2004 às 10:00hs.

www.dieese.org.br/esp Acesso em 21 de novembro de 2005 às 14:00hs.

www.ibge.gov.br/pnad/trabalhoinfantil . Acesso em 6/05/2005 às 10: 50hs.

www.ilo.org/public/portugue/region/ampro/brasilia/ Acesso em 6 de junho de 2005 às 13:00hs.

www.mte.gov.br/resultadosdafiscalizaçãodotrabalho Acesso em 20 de junho de 2005 às 10:30hs. 